\title{
Towards an organisational suicidology
}

John G. Cullen

To cite this article: John G. Cullen (2014) Towards an organisational suicidology, Culture and Organization, 20:1, 40-52, DOI: 10.1080/14759551.2013.852550

To link to this article: https://doi.org/10.1080/14759551.2013.852550

Published online: 05 Dec 2013.

6 Submit your article to this journal $\pi$

Џ Article views: 321

View Crossmark data

47 Citing articles: 4 View citing articles 진 


\title{
Towards an organisational suicidology
}

\author{
John G. Cullen* \\ School of Business, National University of Ireland Maynooth, Maynooth, Ireland
}

(Received 11 January 2013; final version received 3 October 2013)

\begin{abstract}
Suicide is often presented in contemporary popular discourse as an individualistic act of self-destruction, but when academic sociology emerged as a discipline in the nineteenth century, it was initially studied as a cultural phenomenon. Contemporary studies of suicide in the context of organised work, however, have taken a psychologistic turn and increasingly disregard the tradition of studying suicide from cultural perspectives. A culturally informed organisational suicidology has the potential to provide new understandings of how people relate to organisations and work in contemporary societies, as well as providing resources to assist individuals affected by this issue. This article utilises a bibliometric analysis to inform how the research literature has treated suicide as an organisational phenomenon. A definition of organisational suicidology is proposed and future research is suggested with a view to assisting the development of the field.
\end{abstract}

Keywords: organisational suicidology; suicide; culture; death

\section{Introduction}

Suicidology, the study of suicide, its causes, prevention and impact, has been informed by numerous social scientific fields. Within these fields, various research paradigms and methodological traditions have interpreted the phenomenon of suicide in diverse ways (Lester 2011). Large-scale quantitative studies seek to create deterministic models of suicide. Stuckler et al. (2011), for example, present data which demonstrate how increases in unemployment rates correlated with rises in suicide rates over the course of the recession, and 'that the countries facing the most severe financial reversals of fortune, such as Greece and Ireland, had greater rises in suicides (17\% and 13\%, respectively) than did the other countries' (125). Cultural studies of suicide, however, emphasise a more nuanced understanding of how the self is socially constructed by hegemonic workplace habituses. Commenting on the France Télécom suicides, Cederström and Fleming state:

After the suicide scandal broke out, France Télécom's management made a public announcement in which they declared that the deaths were prompted by personal, not professional, causes, thus reflecting [the] view that suicide is dispositional rather than situational. What this fails to take into account, however, is the fact that the post-industrial condition has shattered the boundary between the professional and the personal ... the logic of work is now intimately enmeshed in who we are, regulating even the most 
elementary functions of life. We have become our jobs and therefore an obvious way to end the tyranny of work might be to end ourselves. $(2012,61)$

Both of the above statements apparently reflect different theories about relationships to work in contemporary society: the former that work is so valued to individuals that its loss results in suicidal ideation and the latter that work has become a singularly oppressive value which ultimately renders life toxic and unbearable. Smyth, MacLachlan, and Clare (2003) discuss how the lack of an agreed definition of suicide has impacted on how it is approached and understood within different fields and practices. The World Health Organisation (WHO) (2013) currently defines suicide as 'the act of deliberately killing oneself' which suggests calculated choice and the execution of agency. Preeminent suicidologists such as Shneidman (1985) saw suicide as something which is primarily culturally constructed and 'best understood as a multi-dimensional malaise in a needful individual who defines an issue for which the suicide is perceived as the best solution' (203). Smyth, MacLachlan, and Clare (2003) declare that 'Suicide is not just a medical or psychological problem of the individual. It is more than that it is a problem of society' (4). Suicidology has been strongly connected with sociology as an academic discipline since the publication of Durkheim's Le Suicide in 1897 (Watson 2012).

Durkheim's insistence on 'seeking to establish that what looks like a highly individual and personal phenomenon is explicable through the social structure and its ramifying functions' (Simpson 1970, 10), but the emphasis on understanding suicide as a sociocultural practice appears to have been superseded by medical and psychological definitions of suicide which sees suicide as a personal choice rather than a cultural phenomenon. One analysis of newspaper articles produced over a 12-month timeframe uncovered a tendency 'to report suicide in a way that communicates a message that suicide is a result of personal (incidental) circumstances or clinical or medical reasons, rather than a product of anomie resulting from profound social change' (Cullen 2006, 69).

This article tentatively attempts to introduce suicidology into cultural research on organisations. It does this by reviewing bibliometric data and research literature on work, organisations, culture and suicide to determine where most theory has been developed in this area to date. It then seeks to identify gaps in the literature where future research might be undertaken to contribute to the development of a field of organisational suicidology and advocates related topics which might best inform emergent theory. Following the presentation of bibliometric data and key findings from the review of the associated literature, a definition of organisational suicidology is proposed. As this article is conceptual and exploratory, references will be primarily illustrative, and restrictions of space means that some key works will be referred to, rather explored in detail.

\section{Suicide, organisation and culture in the research literature}

The method adopted for collecting and analysing bibliometric data adopted in this article is that used by Oswick (2009). This approach involves two distinct phases. The first phase aims to identify trends in the development of a body of scholarly knowledge on a particular topic and is particularly useful if the field is small or nascent. The approach involves analysing bibliometric data on peer-reviewed articles indexed in the Social Sciences Citation Index (SSCI), which, over time, 'has become a synonym of 
quality for all social science journals' (Wang, Gilley, and Sun 2012, 509). The second stage is to analyse published outputs designed for a practitioner-based readership and reviews monographs catalogued in the British Library's Online Public Access Catalogue (OPAC) to identify items in which key words appeared either in the main title or sub-title, and which were listed within the 'business and management' subject area.

A search in the title field on the SSCI using the terms 'suicid*' (to cover 'suicide', 'suicidal', etc.) and 'organ*' (for 'organisation', 'organisational', etc.) returned 37 peerreviewed articles. These were reduced to nine articles on the basis that some referred to research conducted by specific organisations (such as the WHO), individuals with suicide prevention roles within health organisations, patient management practices, to processes of psychological organisation and to articles which utilised the term suicide as metaphor (Hubiak and O'Donnell 1997). Although suicide is often mentioned within the business and management literature in relation to organisational and managerial practices, it is rarely discussed in-depth as an organisational phenomenon. For completeness, a similar search was conducted in a business specific database (Business Source Complete) and no additional records were found. When then title search term 'cultur*' was added to the SSCI search, no additional items were found.

To put these findings in context, when the title search was run using the title search term 'suicid*', 19, 698 peer-reviewed articles were returned. Sixty-six per cent of these were found in the psychiatry field alone and the largest numbers were clearly in the areas of medicine and psychology with practically no 'hits' in the areas related to organisational studies. When 'suicid*' was cross-searched with 'cultur*', 166 results were returned. Again, these were primarily in the field of psychiatry or psychology and only one result was returned for a journal listed in the 'management' category. When a title search for 'suicid"' and 'organ'' was conducted on the British Library OPAC, only three relevant results were returned. When 'suicid"' alone was searched, 1993 titles were returned.

Suicide, as an organisational concern, is hugely under-researched. The evidence for this is that less than $0.2 \%$ of books on suicide in the British Library catalogue examine it from an organisational perspective and $0.05 \%$ of research articles in peer-reviewed scholarly journals address the topic. This is not to say that work and the workplace is not a concern of suicidology scholars. An SSCI search of 'suicid*' and 'work*' returned 144 results and a search of 'suicid"' and 'occupat*' (for 'occupation' and 'occupational') returned 43 results. There is a long-standing research tradition which inquires as to which professions have the highest suicide rates. In Le Suicide, Durkheim briefly mentions that some professions are more prone to suicide than others, but fails to explore this assertion in depth. Stack (2001) provided the first systematic evidence to support this claim, finding that certain occupations and professions have higher suicide rates than others. Since this work, most research on the relationship between occupation and suicide has been conducted on a national or regional basis (van Wijngaarden 2003; Agerbo et al. 2007; Woo and Postolache 2008; Andersen et al. 2010; Cohidon et al. 2010; Stallones et al. 2013).

Most of the recent studies on professions appear to study suicide in uniformed organisations such as the police or (more frequently) the military (Boxer and Burnett 1995; Mahon et al. 2005; Kapusta et al. 2010). The openness of these organisations to studies of suicide is perhaps facilitated by their size and the fact that they are public sector organisations who may be mandated to openly declare and address significant human resources (HR) issues when they arise. In traditional epidemiological studies of suicide, occupation is often discussed in relation to the psychological 
well-being of groups on the basis of gender (O'Campo, Eaton, and Muntaner 2004), quality of work environment (Marchand, Demers, and Durand 2005; Dragano et al. 2008; Shimazu and de Jonge 2009) and changing social norms and employment (Pikhart et al. 2004; Kim et al. 2006; Pietila and Rytkonen 2008; Quesnel-Vallee, DeHarney, and Ciampi 2010).

Academic suicidologists have complained that culture has long been under-valued in suicide research and prevention (Hjelmeland 2011), and this difficulty is amplified in organisational studies and studies of organisational culture. This may be due to the fact that suicide as a research issue appears to have been greatly 'psychologised' or 'medicalised' despite academic suicidology, since Durkheim's first contribution, being strongly linked to more sociological investigations. Several social theorists have underlined the growth of the influence which working in post-industrial organisations have on the individual's sense of self-hood in contemporary 'developed' societies (Rose 1990; Hochschild 1983, 1997; Bauman 1998; Cooper 1998). Given that individuals spend more time working in and for organisations and these organisations expect certain forms of self-hood and values from their members (Cederström and Fleming 2012), a huge opportunity for understanding how organisational culture constructs self-hood is possible through an organisational suicidology.

With this in mind, it is important to clarify that the approach to studying organisational culture which best encapsulates the organisational suicidology proposed in this article is one which does not see culture as a variable which can be managed or manipulated for strategic purposes. Much of the popular management literature of the late 1970 s and early 1980 s proposed a view of organisational culture as a monolithic, manageable entity which could be measured, categorised, changed and strengthened with a view to improving organisational performance. Such 'culturalist' (Parker 2000) approaches will not serve an organisational suicidology as they often make universalistic assumptions about how people working together perceive their lived organisational 'reality'. Instead, a more processual approach to studying organisational culture is advocated as it recognises that each organisational culture is fluid, open to multiple interpretations (Martin 1992) and is instantiated at specific organisational locales (Parker 2000). To paraphrase Smircich (1983), an organisational suicidology requires an approach to researching organisational culture as something that an organisation 'is' rather than an organisation 'has'.

Clark and Godney (2000) report that around six million people are bereaved by suicide each year. An organisational suicidology has the potential to contribute to an understanding of how organisational culture acts as support for those bereaved and as a mechanism for helping those who may feel suicidal at work, as well as assisting in the development of managers and HR professionals who can deal with suicide in the workplace (Kinder and Cooper 2009).

Before moving to discussing how organisational suicidology might develop as a distinct sub-field of organisational studies, it is necessary to review that nine relevant pieces of peer-reviewed research sourced from the SSCI review. Durkheim was not unsympathetic to the anguish of the individual who engaged in suicidal ideation, but did not see this as a reason for leaving the phenomenon unexamined:

The incidents of private life which seem the direct inspiration of suicide and are considered its determining causes are in reality only incidental causes. The individual yields to the slightest shock of circumstance because the state of society had made him a ready prey to suicide. $(1970,215)$ 
Durkheim recognised that suicide was not explainable through a single theoretical 'lens', but could be best understood through a spectrum of approaches which demonstrated how the various social relationships that an individual could impact on their propensity to suicidal thought. This framework, which addresses circumstances in which individuals are either highly or lowly integrated with social groups, to perceptions of the level of choice and freedom which individuals belief themselves to possess, has remained highly influential in cultural studies of suicide. As a tool for organising the articles sourced in the SSCI review, this article has applied Durkheim's taxonomy for classifying the different forms of suicide identified. First, each category of suicide is explained. The nine articles are then allocated to each category in order to determine which type of research and theoretical work on suicide in organisations is most common.

When an individual had very low levels integration with social forms - such as religious groups, family relationships, political society, etc.- they enacted a form of suicide which Durkheim named egoistic suicide. Altruistic suicide is undertaken out of a sense of duty to a group. Durkheim sub-divided altruistic suicide into three subfields: obligatory suicide (when an individual kills themselves because society expects them to); optional suicide (where an individual sacrifices themselves for the benefits of a group they are a member of); and acute or mystical suicide (where an individual chooses to take their life for religious or spiritual reasons). The third category is anomic suicide which results when the rules by which society operates are no longer clearly observable or become so incoherent that the individual becomes increasingly isolated and despondent. The final category, fatalistic suicide, is an inversion of anomic suicide. Rather than feeling disconnected because of unclear social rules and norms, the individual becomes oppressed by an excessive amount of them: 'It is the suicide deriving from excessive regulation, that of personas with futures pitilessly blocked and passions violently choked by oppressive discipline' (276). Cederström and Fleming (2012) account for localised suicide 'outbreaks' amongst three groups of workers in shared organisational situations, and in these it is evident that these different groups engage in different categories of suicide. The financial professionals engage in egoistic suicides as a result of rapid disengagement with their organisation and sector during the financial crash and subsequent crisis. The middle managers at France Télécom experienced anomie as 'the majority of the suicides were explicitly linked to dissatisfaction with the restructuring of the firm' (59). The workers at Foxconn experienced fatalistic suicides due to excessive workload and lack of recreational time.

When the nine peer-reviewed research articles which addressed suicide as an organisational phenomenon it is interesting to note that four were concerned with altruistic suicide. Fischer et al. (2008) and Ogden and Hamilton, and Whitcher (2010) explore the activities of 'right-to-die' organisations and Qirko (2009) and Merari et al. (2010) examine the role of altruism in terrorist organisations. One was research best associated with a fatalistic view of suicide (Fridner et al. 2011) and one was concerned with anomic phenomena during an organisational change initiative (Mehlum et al. 2010).

The three remaining articles were variously concerned with a category that did not exist when Durkheim first developed his typology. This is the field of suicide prevention and response which Cederström and Fleming call 'suicide management' (2012, 59). One of these is concerned with the suicide prevention strategies in defence organisations (Zamorski 2011) and another with the training suicide intervention professionals (Evans and Price 2013). The final 'suicide management' article (Kinder and Cooper 2009) stems from the same set of concerns that underpin this article, but 
does so in a way that intends to inform management and organisational practice in relation to 'dealing with' suicide in the workplace as opposed to understanding it as a part of organisational culture. Having reviewed the small body of research literature on suicide from an organisational perspective, this article now turns to consider how an organisational suicidology could be developed through specific forms of research.

\section{Suicidology, culture and organisation}

Much of the published research output on suicide and organisation tends to be either conceptual overviews or are based on large-scale attempts to make sense of suicide as a social fact. As such, they tend to be exploratory and positivist in nature and do not engage with the experiences of members of an organisational culture with workplace suicide or related topics. Although much of the existing literature attempts to make sense of suicide as a phenomenon which is impacted by external factors such as organisational change (Loretto, Platt, and Popham 2010; Lindorff, Worrall, and Cooper 2011) or unemployment (Colledge 1982; Ervasti and Venetoklis 2010), but very little informs how the lived experiences of organisational cultures adapt to assist colleagues with bereavement or preventing suicides or cultivates suicidal states amongst employees. As the bibliometric findings above demonstrate, there is very little research literature on suicide as an organisational phenomenon. As such proposing a sub-field of research within the field of organisational studies requires utilising existing research and frameworks relevant to the subject. In the previous section, Durkheim's taxonomy was used to evaluate the small body of research and here it is utilised as a means by which an organisational suicidology could be constructed through analysis of its theories and methods.

\section{Fatalistic studies of organisational culture}

The Durkheimian category of the 'fatalistic' involves studying the ways in which organisations oppress individuals and impact on their sense of well-being. Studies of death and suffering in organisations may be particularly apposite to this field of study. Bannerjee (2008) demonstrated that many forms of contemporary globalised capitalist endeavour involve death and dispossession. However, studies of death (Bell and Taylor 2011) and suffering (Driver 2007) in organisational studies recognise that organisations typically try to prevent these topics from entering an organisation's culture. Such studies, however, also highlight that research on experiences of death and suffering also provides important opportunities for understanding how meaning is created by organisations and the people who work for them.

Death and suffering are often unexpected intrusions into the lives of many, but as Bell and Taylor (2011) highlight they are often proscribed from organisations and working arranges because of managerial desires to solve the 'problem' of grief and cultural norms which associated death and grieving with negativity. The study of shortterm human resource development interventions and initiatives which attempt to do this has proven useful in providing past opportunities for developing theory in similar contexts. An example related to this was provided by Clair, Maclean, and Greenberg (2002) who researched how North American business school faculty responded to the events of 11 September 2001, by analysing how lecturers dealt with classes traumatised by the death and suffering caused by the large-scale terrorist attack in its immediate aftermath. The intrusion of $9 / 11$ into the routine of business 
education unearthed several findings relative to pedagogical practice, particularly that 'the scholarship of management education is dependent upon more empirical research that focuses on the choices we make as we help our students learn to manage' (53). Studies such as this are useful as they demonstrate that despite managerial attempts to keep death and suffering outside organisations, that they often make their way in, and their presence can provide learning and meaning-making opportunities.

\section{Altruistic studies of organisational culture}

Durkheim discussed altruistic suicide as self-sacrifice for personal, ethical or spiritual reasons. Studies of organisational practices which are not solely focused on generating profits (Land and Taylor 2010; Kenny 2012) demonstrate that trade-offs in personal identity are often made in relation to organisational ideology. As a significant strand of altruistic research involves studying mystical self-sacrifice and borrows heavily from a number of religious traditions, the literature on critical workplace spirituality may be of particular utility to the study of organisational suicide. The introduction of 'new age' spiritual practices into organisations, a phenomenon which has been growing for over 20 years (Heelas 1996; Ackers and Preston 1997) is not an entirely 'innocent' practice and risks harming the subjective well-being of employees or managers subjected to them (Driver 2005; Heelas 2008; Cullen and Turnbull 2012). For example, one of the key components of spiritual management development (Bell and Taylor 2004; Cullen 2009) involves encouraging participating managers to find their 'authentic selves' through fulfilling work. Robertson and Cochrane (1976) found that two of the main reasons for a spike in suicide rates amongst young men aged 25 and under in the UK were an increased societal emphasis on 'self-fulfilment' and a tendency to regard lack of social resources as unassailable obstacles to this self-fulfilment. The belief that work is one of the optional ways by which an employee can discover their authentic self may itself create unrealistic expectations, which have the potential to prove pathological. Investigations into employee resistance to organisational attempts to 'spiritualise' their work places (Cullen 2008) have the potential to 'encourage deeper reflection on the discourses and systems in which they participate' (Cullen 2009, 1249). Similarly, the attempts of bereaved people to 'self-manage' the suicide of a co-worker, rather than participating in suicide management interventions provide learning opportunities to understand how organisational culture (when understood as a process, rather than from a 'culturalist' perspective) can enable solidarity and compassion.

\section{Anomic studies of organisational culture}

Although occupational mental health research articles on suicide generally do not cite Durkheim's concept of anomie, they typically refer to the idea that rapid cultural change can upset the ontological security of managers and employees (Gabriel, Gray, and Goregaokar 2010; Mehlum et al. 2010; Lindorff, Worrall, and Cooper 2011). Such claims run counter to the management fad of orchestrated culture change programmes of the 1980s and 1990s, but have been counterbalanced by studies which focus on how 'happiness' can be maintained during times of organisational change and uncertainty. Research on workplace happiness is a relatively recently new field (Fisher 2010), but it is mentioned here as some of these studies claim to investigate ways to maintain employee happiness during organisational 
change (Loretto, Platt, and Popham 2010). Many discuss data which support the need for organisations to look after employee mental health during times of recession (Berry, Mirabito, and Baun 2010; Schumpeter 2010; Austin and McGuineess 2012). Others advocate the provision of employee assistance or counselling programmes in order to alleviate the anguish caused by undergoing significant workplace change. When suicide is considered in relation to such initiatives, it is usually done so from a preventative suicide management perspective.

\section{Egoistic studies of organisational culture}

In Durkheim's (1970) taxonomy, egoistic suicide is described as 'springing from excessive individualism' (209). This excessive individualism stems from an individuals lack, or loss of, membership in highly integrated groups. For example, Durkheim theorises that higher rates of suicides amongst Protestants when compared to Catholics 'results from it being a less strongly integrated church than the Catholic church' (159). 'Egoistic' approaches have the potential to be useful to scholars interested in the relationship between the individual and organisational culture and what happens when this relationship is severed or weakened. Analysis of the desolation felt by many former professionals and managers, who have been made unemployed during the current recession, can tell us much about the form of self-hood which has been formed in post-industrial organisations in the neo-liberal era (Gabriel, Gray, and Goregaokar 2010). The isolation experienced by redundant managers is just one way of approaching this, and studies of the experience of underemployment (Coulon 2002) or the structural thinning of previously 'thick' workplace bonds (Bolton, Houlihan, and Laaser 2012) can contribute much to developing understandings of the role that organisations play in developing a sense of meaningfulness and identity. In summary, 'egoistic' approaches to the study of organisational culture have the potential to be useful to scholars interested in the relationship between the individual and organisational culture, particularly through analysing what happens when this relationship is severed or weakened.

\section{Developing an organisational suicidology: avenues for research and theory development}

The positivistic nature of much contemporary suicide research and suicide prevention programmes and polices has resulted in suicide remaining a 'hard-to-reach' research area for individuals and organisations. If suicidology is the field of research which attempts to make sense of suicide as a sociocultural phenomenon, organisational suicidology might be summarised as the study of suicide in the context of organisations and organised work. As economic and epidemiological studies of work and suicide are already prevalent, organisational suicidology might instead focus on suicide as a social or cultural issue in organisations and on the ways in which organisational members make sense of suicide amongst their group members, attribute meaning to it in the context of their work and support and protect other organisational/group members.

One difficulty that the development of a culturally centred organisational suicidology faces is a broader societal reluctance to engage with the topic of death. According to Kristeva (2012), secular discourse and philosophy cannot successfully accommodate the inevitability of death, which has meant that secularism is in crisis and religious/ 
spiritual traditions are not. The inability of secular discourse to accommodate mortality may go some way to explaining why studies of death are relatively rare in organisational studies. Similarly, 'suicide management' practices which attempt to prevent suicide from entering organisational discourse often serve to prevent us from understanding the relationship between suicide and organisations, but in themselves can provide useful material for analysis. In this respect, suicide prevention and bereavement may share much with approaches to the study of organisational death that emphasise 'letting go' which can dissolve communal bonds which become more important during times of loss and grief (Seale 1998; Bell and Taylor 2011). Indeed, some 'psychological autopsy' research has demonstrated that the suicidal person engages in developing these ongoing post-life relationships even before they have taken their lives. Suicide prevention and bereavement counselling are important, but from a critical perspective over-emphasising these areas comes at the expense of others, which may further prevent the development of deeper understandings of suicide. However, difficulties in accessing research on a particular field or research subject can tell us much about the object of study (Czarniawska 1998). Critical studies of the material of organisational suicide management programmes (texts, designs, short interventions, etc.) can offer insights into how organisations chose to 'admit' suicide into their organisation. Like critical studies of workplace spirituality, organisational suicidology is concerned with how the self is constructed and experienced in organisational setting. Just as employee experiences of spiritual management development programmes have been studied to explore how spirituality is constructed for (and resisted by) employees (Bell and Taylor 2004; Cullen 2011), organisational well-being and suicide prevention programmes might similarly be subjected to analysis.

Ethnographic interviews with suicide bereaved organisational colleagues about their experiences of suicide may appear an obvious route to suggest for developing an organisational suicidology. Given the highly sensitive nature of the issue, however, access to research participants is not always guaranteed or recommended. One of the informants for Kunda's (1992) study of the 'Tech' corporation reported being instructed by a co-worker, in very strong terms, to keep suicidal thoughts related to workload to themselves. Access issues are somewhat alleviated by information on suicide in organisations through public fora (Ozawa-De Silva 2010; Seignour and Palpaceur 2010; Pezé 2011). Although 'psychological autopsy' practices can deliver insight into the thoughts and beliefs of suicidal people, they can be limited in demonstrating the more fluid ways in which organisational members engage and respond to a suicide. The difficulties that individuals experience in accounting for engagement with these issues can greatly be overcome through the possibilities of autoethnography, where researchers engage with 'hard-to-reach' areas of organisational experience such as being the recipient of bullying (Vickers 2007), gossip (Brewis 2005), engaging with ones gender (Haynes 2013) or spiritual (Cullen 2011) identity in an organisational context. Autoethnography is a form of cultural research which attempts to bridge the personal and the cultural, and it has a particular utility when researching in fields where participants are unlikely to give open, unfettered access. However, the experience of not gaining access to a desired field often provides useful data about that field itself. As autoethnography involves studying cultural groups that the researcher is a member of, access issues are often greatly alleviated.

Although suicide was a key trope in the development of cultural sociology, the study of the phenomenon has appeared to have been overtaken by medicalised and psychologised understandings of the topic. Suicide provides scholars interested in culture 
and organisations with opportunities for learning about how the self is constructed in relation to popular or managerial discourses about organisation. Through critical analysis of texts, interventions, organisational 'suicide management' programmes and autoethnography, the development of a culturally informed organisational suicidology would not only assist in the development of new insights into the experiences of individuals who engage in organised work in late capitalist society, but could also provide important practical insight into genuinely making work cultures most hospitable to employees and managers alike.

\section{References}

Ackers, Peter, and Diane Preston. 1997. "Born Again? The Ethics and Efficacy of the Conversion Experience in Contemporary Management Development." Journal of Management Studies 34 (5): 677-701.

Agerbo, Esben, David Gunnell, Jens Peter Bonde, Preben Bo Mortensen, and Merete Nordentoft. 2007. "Suicide and Occupation: The Impact of Socio-Economic, Demographic and Psychiatric Differences." Psychological Medicine 37 (8): 1131-1140. doi:10.1017/ S0033291707000487.

Andersen, Kirsty, Jacinta Hawgood, Helen Klieve, Kairi Kolves, and Diego De Leo. 2010. "Suicide in Selected Occupations in Queensland: Evidence from the State Suicide Register." Australian and New Zealand Journal of Psychiatry 44 (3): 243-249. doi:10.3109/00048670903487142.

Austin, C., and B. McGuineess. 2012. Breaking the Silence in the Workplace: A Guide for Employers on Responding to Suicide in the Workplace. Kildare/Dublin: Console/The Irish Hospice Foundation.

Bannerjee, Subhabrata Bobby. 2008. "Necrocapitalism." Organization Studies 29 (1): 1541 1563. doi:10.1177/0170840607096386.

Bauman, Zygmunt. 1998. Work, Consumerism and the New Poor, Issues in Society. Buckingham: Open University Press.

Bell, Emma, and Scott Taylor. 2004. "From Outward Bound to Inward Bound': The Prophetic Voices and Discursive Practices of Spiritual Management Development." Human Relations 57 (4): 439-466. doi:10.1177/0018726704043895.

Bell, Emma, and Scott Taylor. 2011. "Beyond Letting Go and Moving On: New Perspectives on Organizational Death, Loss and Grief." Scandinavian Journal of Management 27 (1): 1-10.

Berry, L. L., A. M. Mirabito, and W. B. Baun. 2010. "What's the Hard Return on Employee Wellness Programs?" Harvard Business Review 88 (1): 104-112.

Bolton, Sharon, Maeve Houlihan, and Knut Laaser. 2012. "Contingent Work and Its Contradictions: Towards a Moral Economy Framework." Journal of Business Ethics 111 (1): 121-132. doi:10.1007/s10551-012-1439-7.

Boxer, Peter A., and Carol Burnett. 1995. "Suicide \& Occupation: A Review of the Literature." Journal of Occupational \& Environmental Medicine 37 (4): 442-452.

Brewis, Joanna. 2005. "Signing My Life Away? Researching Sex and Organization." Organization 12 (4): 493-510. doi:10.1177/1350508405052760.

Cederström, Carl, and P. Fleming. 2012. Dead Man Working. Alresford: Zero.

Clair, Judith A., Tammy L. Maclean, and Danna N. Greenberg. 2002. "Teaching Through Traumatic Events: Uncovering the Choices of Management Educators as They Responded to September 11th." Academy of Management Learning \& Education 1 (1): 38-54.

Clark, S. E., and R. D. Godney. 2000. "Impact of Suicide on Relatives and Friends." In International Handbook of Suicide and Attempted Suicide, edited by K. Hawton and K. van Heeringen, 467-484. Chichester: Wiley.

Cohidon, C., G. Santin, B. Geoffrey-Perez, and E. Imbernon. 2010. "Suicide et Activité Professionnelle en France." Revue d'Épidémiologie et de Santé Publique 58 (2): 139150. doi:10.1016/j.respe.2010.01.001.

Colledge, Malcolm. 1982. "Economic Cycles and Health: Towards a Sociological Understanding of the Ompact of the Recession on Health and Ollness." Social Science \& Medicine 16 (22): 1919-1927. 
Cooper, Cary L. 1998. “The Changing Nature of Work.” Community, Work \& Family 1 (3): 313-317.

Coulon, Allana. 2002. "Underemployment Amongst New Zealand Graduates: Reflections from the Lived Experience." New Zealand Journal of Industrial Relations 27 (3): 283.

Cullen, John G. 2006. Meanings, Messages \& Myths: The Coverage and Treatment of Suicide in the Irish Print Media. Dublin: The Health Service Executive.

Cullen, John G. 2008. "Self, Soul and Management Learning: Constructing the Genre of the Spiritualized Manager.” Journal of Management, Spirituality \& Religion 5 (3): 264-292. doi:10.1080/14766080809518707.

Cullen, John G. 2009. "How to Sell your Soul and Still Get Into Heaven: Steven Covey's Epiphany-Inducing Technology of Effective Selfhood." Human Relations 62 (8): 12311254. doi:10.1177/0018726709334493.

Cullen, John G. 2011. "Researching Workplace Spiritualization Through Auto/ethnography." Journal of Management, Spirituality \& Religion 8 (2): 143-164. doi:10.1080/147660 86.2011.581813.

Cullen, John, and Sharon Turnbull. 2012. "The 'Hetero-Ethical' Management Development Rationale." Journal of Management Development 31 (6): 584-593. doi:10.1108/02621 711211230876.

Czarniawska-Joerges, Barbara. 1998. A Narrative Approach in Organization Studies, Qualitative Research Methods. Thousand Oaks, CA: Sage.

Dragano, Nico, Susanne Moebus, Karl-Heinz Jockel, and Raimund Erbel. 2008. "Two Models of Job Stress and Depressive Symptoms: Results from a Population-based Study." Social Psychiatry and Psychiatric Epidemiology 43 (1): 72-78.

Driver, Michaela. 2005. "Reconceptualizing Spirituality in Organizations based on a Psychoanalytically-Grounded Understanding of the Self." Human Relations 58 (9): 1091-1110. doi:10.117710018726705059038.

Driver, M. 2007. "Meaning and Suffering in Organisations." Journal of Organizational Change Management 20 (5): 611-632.

Durkheim, Emile. 1970. Suicide: A Study in Sociology. Translated by John A. Spalding and George Simpson. London: Routledge and Kegan Paul.

Ervasti, H., and T. Venetoklis. 2010. "Unemployment and Subjective Well-being." Acta Sociologica 53 (2): 119-138.

Evans, R. E., and S. Price. 2013. "Exploring Organisational Influences on the Implementation of Gatekeeper Training: A Qualitative Study of the Applied Suicide Intervention Skills Training (ASIST) Programme in Wales." Critical Public Health 23 (2): 213-224. doi:10.1080/09581596.2012.752069.

Fischer, S., C. A. Huber, L. Imhof, R. M. Imhof, M. Furter, S. J. Ziegler, and G. Bosshard. 2008. "Suicide Assisted by Two Swiss Right-to-Die Organisations." Journal of Medical Ethics 34 (11): 810-814. doi:10.1136/jme.2007.023887.

Fisher, C. D. 2010. "Happiness at Work." International Journal of Management Reviews 12 (4): $384-412$.

Fridner, A., K. Belkic, D. Minucci, L. Pavan, M. Marini, B. Pingel, G. Putoto, P. Simonato, L. T. Lovseth, and K. Schenck-Gustafsson. 2011. "Work Environment and Recent Suicidal Thoughts Among Male University Hospital Physicians in Sweden and Italy: The Health and Organization Among University Hospital Physicians in Europe (HOUPE) Study." Gender Medicine 8 (4): 269-279. doi:10.1016/j.genm.2011.05.009.

Gabriel, Y., D. E. Gray, and H. Goregaokar. 2010. "Temporary Derailment or the End of the Line? Managers Coping with Unemployment at 50.” Organization Studies 31 (12): 1687-1712.

Haynes, Kathryn. 2013. "Sexuality and Sexual Symbolism as Processes of Gendered Identity Formation: An Autoethnography of an Accounting Firm." Accounting, Auditing \& Accountability Journal 26 (3): 374-398. doi:10.1108/09513571311311865.

Heelas, Paul. 1996. The New Age Movement: The Celebration of the Self and the Sacralization of Modernity. Oxford/Cambridge, MA: Blackwell Pub.

Heelas, Paul. 2008. Spiritualities of Life: New Age Romanticism and Consumptive Capitalism. Malden, MA: Blackwell Pub.

Hjelmeland, Heidi. 2011. "Cultural Context is Crucial in Suicide Research and Prevention." Crisis: The Journal of Crisis Intervention and Suicide Prevention 32 (2): 61-64.

Hochschild, Arlie Russell. 1983. The Managed Heart: Commercialization of Human Feeling. Berkeley: University of California Press. 
Hochschild, Arlie Russell. 1997. The Time Bind: When Work Becomes Home and Home Becomes Work. 1st ed. New York: Metropolitan Books.

Hubiak, William A., and Susan Jones O'Donnell. 1997. "Downsizing: A Pervasive Form of Organizational Suicide." National Productivity Review 16 (2): 31-36.

Kapusta, N. D., M. Voracek, E. Etzersdorfer, T. Niederkrotenthaler, K. Dervic, P. L. Plener, E. Schneider, C. Stein, and G. Sonneck. 2010. "Characteristics of Police Officer Suicides in the Federal Austrian Police Corps." Crisis: The Journal of Crisis Intervention and Suicide Prevention 31 (5): 265-271.

Kenny, Kate. 2012. “'Someone Big and Important': Identification and Affect in an International Development Organization." Organization Studies 33 (9): 1175-1193. doi:10.1177/ 0170840612448156.

Kim, Il-ho, C. Muntaner, Young-Ho Khang, Domyung Paek, and Sung-Il Cho. 2006. "The Relationship between Nonstandard Working and Mental Health in a Representative Sample of the South Korean Population." Social Science \& Medicine 63 (3): 566-574.

Kinder, A., and C. L. Cooper. 2009. "The Costs of Suicide and Sudden Death within an Organization.” Death Studies 33 (5): 411-419. doi:10.1080/07481180902805624.

Kristeva, Julia. 2012. "A Tragedy and a Dream: Disability Revisited. The Michael Devlin Lecture." In The Wounded Body: Human Vulnerability and Disability in a Finite World. Maynooth: Saint Patrick's College.

Kunda, Gideon. 1992. Engineering Culture: Control and Commitment in a High-Tech Corporation. Philadelphia, PA: Temple University Press.

Land, Chris, and Scott Taylor. 2010. "Surf's Up: Work, Life, Balance and Brand in a New Age Capitalist Organization.” Sociology 44 (3): 395-413.

Lester, D. 2011. "The Cultural Meaning of Suicide: What Does that Mean?" Omega-Journal of Death and Dying 64 (1): 83-94. doi:10.2190/OM.64.1.f.

Lindorff, M., L. Worrall, and C. Cooper. 2011. "Managers' Well-being and Perceptions of Organizational Change in the UK and Australia." Asia Pacific Journal of Human Resources 49 (2): 233-254.

Loretto, W., S. Platt, and F. Popham. 2010. "Workplace Change and Employee Mental Health: Results from a Longitudinal Study.” British Journal of Management 21 (2): 526-540.

Mahon, Martin J., John P. Tobin, D. A. Cusack, C. Kelleher, and M. Kevin Malone. 2005. "Suicide Among Regular-Duty Military Personnel: A Retrospective Case-control Study of Occupation-specific Risk Factors for Workplace Suicide." American Journal of Psychiatry 162 (9): 1688-1696.

Marchand, A., A. Demers, and P. Durand. 2005. "Does Work Really Cause Distress? The Contribution of Occupational Structure and Work Organization to the Experience of Psychological Distress.” Social Science \& Medicine 61 (4): 1-14.

Martin, Joanne. 1992. Culture in Organizations: Three Perspectives. Oxford: Oxford University Press.

Mehlum, L., T. Jorgensen, L. My Diep, and L. Nrugham. 2010. "Is Organizational Change Associated with Increased Rates of Readmission to General Hospital in Suicide Attempters? A 10-year Prospective Catchment Area Study." Archives of Suicide Research 14 (2): $171-181$.

Merari, A., J. Fighel, B. Ganor, E. Lavie, Y. Tzoreff, and A. Livne. 2010. “Making Palestinian 'Martyrdom Operations'/'Suicide Attacks': Interviews With Would-Be Perpetrators and Organizers." Terrorism and Political Violence 22 (1): 102-119. doi:10.1080/0954655 0903409403.

O'Campo, P., W. W. Eaton, and C. Muntaner. 2004. "Labour Market Experience, Work Organization, Gender Inequalities and Health Status: Results for a Prospective Analysis of US Employed Women.” Social Science \& Medicine 58 (3): 585-594.

Ogden, R. D., W. K. Hamilton, and C. Whitcher. 2010. "Assisted Suicide by Oxygen Deprivation with Helium at a Swiss Right-to-Die Organisation." Journal of Medical Ethics 36 (3): 174-179. doi:10.1136/jme.2009.032490.

Oswick, Cliff. 2009. "Burgeoning Workplace Spirituality? A Textual Analysis of Momentum and Directions." Journal of Management, Spirituality and Religion 6 (1): 15-25.

Ozawa-De Silva, Chikako. 2010. "Shared Death: Self, Sociality and Internet Group Suicide in Japan.” Transcultural Psychiatry 47 (3): 392-418. doi:10.1177/1363461510370239. 
Parker, Martin. 2000. Organizational Culture and Identity: Unity and Division at Work. London: Sage.

Pezé, Stéphan. 2011. "Thinking the Unthinkable: Managerialization of Work Related Suicides as a Framing Process." EGOS, Gothenberg.

Pietila, Ilkka, and Marja Rytkonen. 2008. "Coping with Stress and Disstress: Russian Men and Women Talking about Transition, Stress and Health.” Social Science \& Medicine 66 (2): $327-338$.

Pikhart, H., M. Bobak, A. Pajak, S. Malyutina, R. Kubinova, R. Topor, H. Sebakova, Y. Nikitin, and M. Marmot. 2004. "Psychosocial Factors at Work and Depression in Three Countries of Central and Eastern Europe." Social Science \& Medicine 58 (8): 1475-1482.

Qirko, H. N. 2009. "Altruism in Suicide Terror Organizations." Zygon 44 (2): 289-322. doi:10.1111/j.1467-9744.2009.01001.x.

Quesnel-Vallee, Amelie, Suzanne DeHarney, and Antonio Ciampi. 2010. "Temporary Work and Depressive Symptoms: A Propensity Score Analysis." Social Science \& Medicine 70 (12): $1982-1987$.

Robertson, Alex, and Raymond Cochrane. 1976. “Attempted Suicide and Cultural Change: An Empirical Investigation.” Human Relations 29 (9): 863-883.

Rose, Nikolas S. 1990. Governing the Soul: The Shaping of the Private Self. London: Routledge.

Schumpeter. 2010. "Mens Sana in Corporation Sano." The Economist, p. 65.

Seale, C. 1998. "Theories and Studying the Care of Dying People." British Medical Journal 317 (7171): $1518-1519$.

Seignour, Amelie, and Florence Palpacuer. 2010. "Restructuring, Violence at Work and Managerial Rhetoric: Learning from the Case of France Telecom.” EURAM 2010: Back to the Future, Tor Vergata University, Rome.

Shimazu, A., and J. de Jonge. 2009. "Reciprocal Relations between Effort-Reward Imbalance at Work and Adverse Health: A Three-Wave Panel Survey." Social Science \& Medicine 68 (1): $60-68$.

Shneidman, Edwin S. 1985. Definition of Suicide. New York: Wiley.

Simpson, George. 1970. "Editor's Preface." In Suicide: A Study in Sociology, edited by George Simpson, 9-12. London: Routledge and Kegan Paul.

Smircich, Linda. 1983. "Concepts of Culture and Organizational Analysis." Administrative Science Quarterly 28 (3): 339-358.

Smyth, Caroline, Malcolm MacLachlan, and Anthony W. Clare. 2003. Cultivating Suicide? Destruction of Self in a Changing Ireland, Pressure Points in Irish society. Dublin: Liffey Press.

Stack, Steven. 2001. "Occupation and Suicide.” Social Science Quarterly 82 (2): 384-396. doi:10.1111/0038-4941.00030.

Stallones, Lorann, Timothy Doenges, Bryan J. Dik, and Morgan A. Valley. 2013. "Occupation and Suicide." American Journal of Industrial Medicine 56 (11): 1290-1295. doi:10.1002/ ajim.22228.

Struckler, David, Sanjay Basu, Marc Suhrcke, Adam Coutts, and Martin McKee. 2011. "Effects of the 2008 Recession on Health: A First Look at European data." The Lancet 378 (9786): $124-125$.

Vickers, Margaret H. 2007. "Autoethnography as Sensemaking: A Story of Bullying." Culture \& Organization 13 (3): 223-237. doi:10.1080/14759550701486555.

Wang, Greg G., Jerry W. Gilley, and Judy Y. Sun. 2012. "The "Science of HRD Research": Reshaping HRD Research through Acientometrics." Human Resource Development Review 11 (4): 500-520. doi:10.1177/1534484312452265.

Watson, Tony J. 2012. Sociology, Work and Organisation. 6th ed. London: Routledge.

WHO (World Health Organization). 2013. Health Topics: Suicide. WHO. Accessed July 2, 2013. http://www.who.int/topics/suicide/en/.

van Wijngaarden, Edwin. 2003. "An Exploratory Investigation of Suicide and Occupational Exposure" Journal of Occupational and Environmental Medicine 45 (1): 96-101. doi:101.1097/01.jom.0000048167.87707.6f.

Woo, Jong-Min, and Teodor T. Postolache. 2008. "The Impact of Work Environment on Mood Disorders and Suicide: Evidence and Implications." International Journal on Disability and Human Development 7 (2): 185-200.

Zamorski, M. A. 2011. "Suicide Prevention in Military Organizations." International Review of Psychiatry 23 (2): 173-180. doi:10.3109/09540261.2011.562186. 